ORIGINAL ARTICLE

\title{
The criminal purchase of firearm ammunition
}

\author{
G E Tita, A A Braga, G Ridgeway, G L Pierce
}

Injury Prevention 2006;12:308-311. doi: 10.1136/ip.2006.013052

See end of article for authors' affiliations ......................

Correspondence to: Professor G E Tita, University of CaliforniaIrvine, Criminology, Law, and Society, 2307 'Socia Ecology II, Irvine, CA 92697-7080, USA; gtita@uci.edu

Accepted 4 August 2006
Objective: Laws that prohibit certain individuals from owning firearms also pertain to ammunition. Whereas retail sales of firearms to criminals are regularly disrupted by instant background checks, sales of ammunition are essentially unchecked and the rate at which criminals acquire ammunition is unknown. This research describes the ammunition market and estimates the rate at which criminals are acquiring ammunition.

Design: Criminal background checks conducted on individuals purchasing ammunition in the City of Los Angeles in April and May 2004.

Setting: Los Angeles, CA, USA.

Subjects: Ammunition purchasers.

Main outcome measures: Criminal activity that prohibits one from owning, purchasing, or possessing ammunition.

Results: $2.6 \%$ (95\% Cl $1.9 \%$ to $3.2 \%$ ) of ammunition purchasers had a prior felony conviction or another condition that prohibited them from possessing ammunition. During the study period prohibited possessors purchased 10050 rounds of ammunition in Los Angeles.

Conclusions: These estimates suggest that monitoring ammunition transactions may help reduce the supply of ammunition to criminals and the frequency of injuries from felonious gun assaults. Such a record can also provide information for generating leads on illegal firearm possession.
$\mathrm{F}$ rom 1993-96, emergency rooms in the United States treated an estimated 413186 incidents of non-fatal firearm injuries stemming from causes ranging from gunshot wounds, injuries sustained while trying to elude gunfire, lacerations from recoil, and being struck by a firearm. ${ }^{1}$ Over this period, an estimated 7630 people were treated annually for injuries resulting from purposefully being struck by a gun. This number, however, pales in comparison to the nearly 87000 injuries caused by being struck by a bullet fired from a gun. Clearly, guns without ammunition are much less dangerous than loaded ones and, besides the fear that guns induce, the unloaded gun is no more dangerous than any other blunt object. Unlike the public health view on drug policy, which recognizes the importance of limiting access to both the agent of harm (the narcotic) and the instrument of delivery (for example, syringe), gun policy has focused primarily on limiting access to the instrument of delivery, firearms, while eschewing efforts to limit access to ammunition, the actual agent of harm.

Gun violence has decreased over the past decade, yet many Americans still die by gunfire and, of course, many more are still affected by non-fatal gun violence. In 2004, there were 11344 gun murders, 164998 gun assaults, and 162938 gun robberies. ${ }^{2}$ In 2003, there were 16907 suicides with firearms. ${ }^{3}$ Advocates on all sides of the gun control debate in the United States agree that policies and interventions that make guns and ammunition less available to those who are prone to violence deserve high priority, will save lives, and reduce the burden of gun violence on society. One broad class of strategies is designed to limit access to different kinds of weapons by different kinds of people. ${ }^{4}$ The basic policy idea is to restrict access to firearms and ammunition by the "bad guys" without denying access to the "good guys". ${ }^{5}$ Existing firearms regulations in the United States that prohibit certain individuals from purchasing or possessing a firearm also apply to the purchase and possession of ammunition. While there has been considerable policy action at the federal, state, and local level to identify and screen out ineligible purchasers of firearms through criminal background checks, there has been little action to identify and screen out disqualified buyers from illegally acquiring ammunition. Most countries restrict certain individuals, such as violent offenders and those with certain mental illnesses, from possessing firearms but the United Nations Group of Experts notes that "measures to control small arms and light weapons would not be complete if they did not include ammunition and explosives". ${ }^{6}$ Clearly ammunition makes guns much more lethal. If gun-using criminals could be hindered from obtaining ammunition, it follows that gun violence may decline. Furthermore, recent research suggests that even within an urban center plagued by gun violence, guns are more readily available for purchase than ammunition. ${ }^{7}$ This finding suggests that greater efforts to prevent criminal access to ammunition may be more effective in reducing firearm injury than further limiting access to firearms.

\section{REGULATING AMMUNITION SALES AND SCREENING AMMUNITION PURCHASERS}

A number of nations as well as some US states currently require ammunition purchasers to have valid identification cards and/or firearms licenses. Proposed legislation in California (SB 357) would further require ammunition dealers in California to log all ammunition purchases and their purchasers in a state database. Although this bill failed in 2005, state law has not preempted city ordinances enacted in Los Angeles, San Francisco, Oakland, and several other California cities to regulate ammunition commerce. These statutes have tougher proof of identification standards (state issued identification card and the purchaser's fingerprint) and require the seller to retain documentation of all

Abbreviations: ATF, Bureau of Alcohol, Firearms, Tobacco and Explosives; DOJ, Department of Justice; FFL, Federal Firearms Licensee; LAPD, Los Angeles Police Department. 
ammunition purchasers in a non-electronic "ammunition $\log ^{\prime \prime}$.

Underpinning these legislative efforts is the belief that prohibited possessors are currently purchasing ammunition at licensed dealers and could be prevented from doing so through criminal background checks and transaction records. Currently there is no direct research evidence to support this position and efforts against this legislation have pointed out this lack of evidence. The Citizens Committee for the Right to Keep and Bear Arms (CCRKBA) correctly noted following the defeat of SB 1152 that "there is no existing data to suggest that an ammunition purchase registry will have any positive impact on crime ${ }^{\prime \prime 8}$ (authors' italics). Similarly, the National Association of Firearms Retailers criticized the measure, noting that "no valid public safety purpose will be advanced by burdening our members in California with keeping a registry of perfectly legal ammunition sales and law-abiding ammunition purchasers. We are aware of no scientifically valid study that concludes an ammunition registry would be an effective law enforcement tool"s (authors' italics).

As noted above, there is reason to believe that targeting retail ammunition sales will in fact impact levels of firearm injury. Recent ethnographic research on the workings of illegal guns markets in Chicago suggests that it was more difficult for criminals to acquire ammunition than guns. ${ }^{7}$ Most youth reported trouble with securing ammunition and faced considerable price markups compared to the legal market. If it is true that for many criminals ammunition is scarce then effective screening procedures or transaction record keeping for ammunition purchases at retail outlets could be used to good effect in reducing an important supply line of ammunition.

In this study, we sought to learn more about the retail market in ammunition by examining bullet and shotgun shell purchases in the City of Los Angeles, which passed a city ordinance in 1998 requiring proof of identification and a thumbprint (55.11 LAMC). We examined the characteristics of sales conducted in the City of Los Angeles, California with a particular focus on the purchasers' criminal history. We also explored the frequency in which prohibited possessors acquire ammunition from licensed dealers. Our results indicate that prohibited possessors acquired about 10000 rounds of ammunition during the two month study period.

\section{DATA}

These data were collected as part of a US Department of Justice (DOJ) funded study aimed at understanding and disrupting the illegal gun market serving criminals and youth in Los Angeles. Local ordinance requires every Federal Firearms Licensee (FFL) in Los Angeles that sells ammunition to maintain ammunition purchase logs on all transactions, which the Los Angeles Police Department (LAPD) Gun Unit periodically collects. The data recorded for each transaction are handwritten into the ammunition log and include purchaser-specific data, as well as purchase-specific information. Identifying information for each purchaser includes name, age, sex, date of birth, address, thumbprint, and a driver's license/state issued identification number. Data also include the type and quantity of ammunition purchased along with the date for each transaction.

Our study uses ammunition log data to examine purchases made in the City of Los Angeles during the months of April and May 2004. During the study time period, there were only 15 FFLs in all of Los Angeles that sold ammunition: eight sporting goods stores, three firing ranges, two law enforcement facilities, one war surplus store, and one small business that reloads ammunition for sale. As part of the DOJ study, the LAPD Gun Unit collected the completed logs from 10 businesses and handed these records over to the Southern
California Regional Crime Gun Center operated by the Bureau of Alcohol, Tobacco, Firearms, and Explosives (ATF). We excluded the two law enforcement facilities because they sell only to law enforcement employees, who by definition cannot have a criminal background. Limited availability of LAPD officers for collecting the data on ammunition purchases during the study's time period resulted in data not being collected from the ammunition reload business, one of the sporting goods stores, and one of the firing ranges. As such, these ammunition dealers were excluded from our analyses. ATF personnel computerized the data from the 10 remaining FFLs. For each transaction in the ammunition logs, ATF personnel checked whether the purchaser appeared in the National Criminal Information Center (NCIC) data or in the California Department of Justice's Criminal History files. They recorded the full criminal histories of the complete sample of ammunition purchasers with criminal backgrounds.

Seven of the observed ammunition retailers are in the San Fernando Valley, the northern half of the City of Los Angeles. These retailers represent approximately $93 \%$ of the ammunition transactions recorded during the study period. None of the business premises of the 10 ammunition retailers were located near the high crime South Los Angeles area of the city. Although this area leads the city in total homicide and total gun crime, none of the "local" places to purchase ammunition actually falls within the Los Angeles city limits. According to the LAPD and ATF, the likely ammunition supply for this area consists of the nearly one dozen ammunition dealers near South Los Angeles which are located just outside of the city limits in the surrounding Los Angeles County municipalities, and therefore not required to record ammunition purchases. Thus, our analysis of Los Angeles' ammunition data represents a snapshot of the ammunition market in the northern half of the city. Though it is only a portion of the city, in 2002 the San Fernando Valley's 1.4 million residents comprised $37 \%$ of the city's population. By itself it would rank as the seventh largest city in the United States.

\section{RESULTS}

In April and May 2004 there were 2031 unique purchasers who made 2540 transactions that resulted in the sale of 4823 boxes of ammunition that totaled 436956 rounds.

\section{Who buys ammunition?}

Though most of the ammunition purchasers reside locally, a small number of non-California residents $(n=60)$ also purchased ammunition in the city. It is not clear whether these individuals purchased ammunition while visiting or if these are new local residents who have not yet changed their official place of residence. Among the remaining 97\% of purchasers $(n=1971)$, Los Angeles city residents make up $70 \%$ of the purchasers and another 19\% reside within Los Angeles County. The overwhelming majority of purchasers live within the San Fernando Valley, which is to be expected as ammunition prices are relatively stable across merchants. An informal survey of local ammunition dealers in and around Los Angeles indicated that a 500 round box of lower end .22 ammunition ranged from $\$ 14$ to $\$ 16$, a difference for which we do not expect consumers to travel great distances given that local gas process peaked at $\$ 2.36$ per gallon during this period.

While $92 \%$ of gun purchasers in Los Angeles County are male, ${ }^{9}$ a slightly larger percentage $(96 \%)$ of ammunition purchasers in the city are male. As shown in table 1, bullet purchasers are also more likely to fall into the $21-24$ years age category (15\%) than gun purchasers $(9 \%)$. 
Table 1 Age distribution of Los Angeles county handgun purchasers and Los Angeles city ammunition purchasers

\begin{tabular}{lcc}
\hline Age (years) & Handguns (county) & Ammunition (city) \\
\hline $21-24$ & $9.0 \%$ & $15.4 \%$ \\
$25-34$ & $23.5 \%$ & $28.6 \%$ \\
$35-44$ & $25.3 \%$ & $24.1 \%$ \\
$45-54$ & $24.1 \%$ & $18.0 \%$ \\
$55-64$ & $12.9 \%$ & $8.7 \%$ \\
$65+$ & $5.2 \%$ & $2.9 \%$ \\
\hline
\end{tabular}

\section{Should they be buying?}

During the study period, $6.5 \%$ of ammunition purchasers had a criminal record. A criminal record, however, is not sufficient for prohibiting a purchaser from buying ammunition. Federal law prohibits convicted felons and domestic violence misdemeanants from acquiring ammunition. Additionally, California state law includes provisions that prohibit individuals convicted of violent misdemeanors from purchasing and possessing ammunition. Of the study's ammunition purchasers, $1.5 \%$ had prior felony convictions; 13 drug related felonies, eight grand theft or burglary felonies, two cases of felony check fraud, two weapon offenses, and one case each of extortion, stalking, and sex with client (details of two other felony convictions were unknown). An additional 1.1\% of the purchasers had other conditions (for example, misdemeanor assault or an active restraining order) that prohibited their purchases. Table 2 summarizes these findings.

These prohibited possessors made $2.8 \%$ (71/2540) of all transactions and collectively purchased 2.3\% (10 050/ 436 956) of the rounds sold in the two month study period. They generally purchase the same kinds of ammunition as legal purchasers. For example among prohibited possessors, $40 \%$ purchased $9 \mathrm{~mm}$ ammunition while $38 \%$ of legal purchasers bought $9 \mathrm{~mm}$ ammunition. By comparison, the Violence Prevention Research Program ${ }^{9}$ reported that $0.8 \%$ of attempted gun purchases statewide involved a prohibited possessor in 2000, but the background check and 10 day waiting period interrupted those purchases. While the Los Angeles ammunition ordinance requires ammunition transactions to be recorded, there is no instant check and before 2004 the $\operatorname{logs}$ were only referenced when police were following up on specific crimes. As a result prohibited possessors were able to purchase ammunition with little risk of detection.

Table 2 Criminal background of ammunition purchasers

\begin{tabular}{lrl}
\hline & $\mathbf{n}$ & $\begin{array}{l}\text { Percentage during study } \\
\text { period }(95 \% \mathrm{Cl}) \dagger\end{array}$ \\
\hline $\begin{array}{l}\text { Unique purchasers } \\
\text { Purchasers with a criminal record* }\end{array}$ & 2031 & \\
$\begin{array}{l}\text { Purchasers prohibited from } \\
\text { purchasing ammunition }\end{array}$ & 52 & $2.6(1.9$ to 3.2$)$ \\
$\quad \begin{array}{l}\text { Felony conviction } \\
\text { Non-felony offense }\end{array}$ & 30 & $1.5(1.0$ to 2.0$)$ \\
& 22 & $1.1(0.6$ to 1.5$)$ \\
\hline
\end{tabular}

*Having a criminal record does not necessarily prohibit ammunition purchases.

tThe $95 \%$ confidence intervals are computed as if April and May are representative of a stationary process of ammunition purchasing.

\section{CONCLUSIONS}

These data suggest that, despite having to identify themselves through showing a driver's license, leaving a fingerprint, and creating a record of the transaction, prohibited purchasers still buy ammunition at Los Angeles dealers. Though some ineligible buyers may be deterred by these requirements and make purchases at dealers beyond the city limits, the lack of enforcement of existing laws means that prohibited persons still complete the required elements of the transaction and walk out of the store with ammunition.

In an attempt to stem the flow of ammunition to prohibited purchasers, policy makers might consider extending instant background checks to include ammunition purchases. A criminal background check would be an unnecessary inconvenience in about $97 \%$ of ammunition transactions in Los Angeles. However, in just two months, prohibited persons acquired some 10050 rounds through retail outlets. A background check would eliminate illegal ammunition transactions at retail outlets and denied ammunition purchase rate would probably converge to around $0.8 \%$, the denial rate for firearms. Similar to the illegal market substitution effects associated with the passage of the Brady Law, ${ }^{10}{ }^{11}$ prohibited purchasers seem likely to exploit alternative sources of ammunition such as unregulated private sellers operating in the secondary firearms markets.

An alternative policy to the instant criminal background check would be to use the ammunition transaction records as an intelligence gathering tool for law enforcement. Routine examination of ammunition purchasers could be used to identify prohibited persons who illegally possess ammunition and, most likely, illegally possess firearms as well. The ammunition logs have been used as a basis for developing probable cause in securing search warrants, some of which have resulted in the recovery of illegal firearms [conversation with the supervising attorney of the Gun Violence Section of the Los Angeles City Attorney's office].

At present, the key impediment to the utility of the Los Angeles ammunition log for law enforcement is that it is restricted to dealers located within the city limits. Los Angeles residents can easily cross into other areas of the county and purchase untraceable ammunition. Given the dearth of purchasers residing in South Los Angeles, and that these neighborhoods have severe gun violence problems, it is clear that Los Angeles retailers are not the source of this area's ammunition supply. Illegal street sales, mail order purchases, and retail purchases outside the city limits are all possible ammunition sources, none of which is currently monitored. A first step in turning the ammunition log into a useful intelligence tool for South Los Angeles would be to have neighboring municipalities cooperate in a concerted effort to collect similar data on ammunition transactions. Although our study focused on one part of Los Angeles, our findings have implications for other states and nations that monitor firearm sales but not ammunition purchases; without monitoring or enforcement, prohibited purchasers are not completely deterred from purchasing ammunition.

\section{Implication for prevention}

Relative to firearms and ammunition in legal hands, guns and ammunition in the hands of a prohibited possessor are at high risk of being used in violent crime. ${ }^{12}$ Monitoring ammunition transaction can reduce that risk by either following those criminal purchasers back to their firearms or interrupting criminal purchases at the point-of-sale with an instant check. Expanding the monitoring to the county level or the state level may result in FFLs beyond the jurisdiction of the legislation becoming easy sources for illicit ammunition purchases. Due to less stringent gun controls, dealers in Nevada and Arizona are already noteworthy outof-state sources of crime guns recovered in Los Angeles ${ }^{13}$ and seem likely to become illicit sources of ammunition. A statewide program might push the illegal ammunition 


\section{Key points}

- Individuals prohibited from purchasing firearms and ammunition continue to purchase ammunition through licensed dealers because existing laws are rarely enforced.

- In the City of Los Angeles during the study period, prohibited individuals purchased 10050 rounds of ammunition, $2.8 \%$ of all transactions.

- Firearm policy should adopt the public health approach, which recognizes the importance of addressing both the mechanism of delivery (the gun) and the agent of harm (the bullet) in order to be effective in reducing gunshot injuries.

purchases out of the state and, therefore, increase the "effective price" of illegal ammunition sales on the streets of Los Angeles. ${ }^{14}$ Increasing the costs associated with the illegal acquisition of ammunition may cause criminals to economize on firearm use and, in turn, reduce gun violence. The potential for substitution to alternative black market sources is a concern for any gun market intervention. ${ }^{15}$ Nonetheless, given the heavy burden of gun violence, policymakers need to consider policy interventions that remove easy opportunities for violent gun-using criminals to arm themselves.

\section{Study limitations}

This study used administrative data from 10 of 13 non-law enforcement ammunition retailers in the City of Los Angeles over a two month period. Therefore, this study's findings may not be representative of all ammunition transactions in the greater Los Angeles area nor in other cities around the world. Although the Los Angeles city ordinance requires dealers to document all ammunition transactions there may be noncompliance. Compliance could be associated with whether or not the purchaser is eligible to possess ammunition. ATF completed the background checks for all purchasers based on names and state issued IDs from the hand written logs collected from the retailers. Accurate criminal history checks depended on this information being written correctly and clearly on the forms.

\section{ACKNOWLEDGEMENTS}

This research was funded by a grant from the National Institute of Justice No 2001-IJ-CX-0028. The funder was not involved in the design or conduct of this study.

\section{Authors' affiliations}

G E Tita, Criminology, Law and Society, University of California-Irvine, Irvine, CA, USA

A A Braga, John F Kennedy School of Government at Harvard University, Cambridge, MA, USA

G Ridgeway, Statistics Group, RAND, Santa Monica, CA, USA

G L Pierce, College of Criminal Justice, Northeastern University, Boston, MA, USA

Competing interests: none.

\section{REFERENCES}

1 Hootman JM, Annest JL, Mercy JA, et al. National estimates of non-fatal firearm related injuries other than gunshot wounds. Inj Prev 2000;6:268-74.

2 Bureau of Justice Statistics. Key facts at a glance: Crimes committed with firearms, 1973-2004. Available at http://www.ojp.usdoj.gov/bjs/glance/ tables/guncrimetab.htm (accessed May 2006).

3 NCHS Vital Statistics System, Office of Statistics and Programming, National Center for Injury Prevention and Control. Available at http://www.cdc.gov/ ncipc/wisqars (accessed July 2006).

4 Zimring FE. Firearms, violence, and public policy. Sci Am 1991;265:48-54.

5 Cook PJ, Moore MH, Braga AA. Gun control. In:Wilson JQ, Petersilia J (eds). Crime: public policies for crime control. Oakland, CA: Institute for Contemporary Studies Press, 2002.

6 United Nations Report of the Group of Experts on the Problem of Ammunition and Explosives (A/54/155). Submitted by the UN Secretary-General June 29, 1999.

7 Cook PJ, Ludwig J, Venkatesh S, et al. Underground gun markets, NBER working paper 11737. Cambridge, MA: National Bureau of Economic Research, 2005.

8 CCRKBA calls California Senate Bill 1152 'regulatory excess' [press release]. Bellevue, WA: Citizens Committee for the Right to Keep and Bear Arms, June 23, 2004.

9 Violence Prevention Research Program. Handgun commerce in California, 2000. Sacramento, CA: Violence Prevention Research Program, 2004.

10 Ludwig J, Cook PJ. Homicide and suicide rates associated with the implementation of the Brady Handgun Violence Prevention Act. JAMA 2000;284:585-91.

11 Cook PJ, Braga AA. Comprehensive firearms tracing: strategic and investigative uses of new data on firearms markets. Ariz $L$ Rev 2001;43:277-309.

12 Wright MA, Wintemute GJ, Claire BE. People and guns involved in denied and completed handgun sales. Inj Prev 2005;11:247-50.

13 US Bureau of Alcohol, Tobacco, and Firearms. Crime gun trace reports (1999): national report. Washington, DC: US Bureau of Alcohol, Tobacco, and Firearms, 2000.

14 Moore MH. Achieving discrimination on the effective price of heroin. Am Econ Rev 1973;63:270-7.

15 Wellford C, Pepper J, Petrie C (eds). Firearms and violence: a critical review. Washington, DC: The National Academies Press, 2005. 